\title{
The Inner Clues of TaoTeChing
}

\author{
YI Fu-sheng \\ Graduate School of Chinese Academy of Social Sciences, Beijing, China
}

\begin{abstract}
TaoTeChing is one of the most important classics of Chinese literature. There are inner clues in TaoTeChing. Lao-tzu found that all the visible things are produced or born by something, which means that these observable things could not be the ultimate source of the universe. The ultimate source of the universe must be invisible and has no color or sound. Lao-tzu called it the "Tao". On this basis, Lao-tzu got a series of conclusions including that the "Tao" runs spontaneously only following the law of itself and is not controlled by anything; The "Tao" is characterized by weakness and doing nothing; etc.. In this paper, we try to recreate the process of Lao-tzu's construction of his ideology.
\end{abstract}

Keywords: TaoTeChing, Lao-tzu, Chinese philosophy

\section{Introduction}

TaoTeChing (道德经) is one of the most important classics of Chinese literature. In this book, Lao-tzu (老 子), the author, described a secret thing called the “Тao" (道). The “Tao" is the creator and mother of everything in the universe and everything will return to the "Tao" after they die and disappear. Besides, the “Tao" has many features: The "Tao" has no shape, no color and no sound; The "Tao” runs spontaneously only following the law of itself and is not controlled by anything; The "Tao" is characterized by weakness and doing nothing; etc.. Lao-tzu also believed that human society should follow the "Tao", otherwise, it will not last for long. How did Lao-tzu get those conclusions? He did not have a systematic and detailed proof. The researchers in different periods of history did not get to the bottom, either. They said it was too mysterious to understand. This paper tries to explain how Lao-tzu formed the ideology of the "Tao" mostly based on TaoTeChing itself.

\section{The Ultimate Source of the Universe}

Many civilizations in the world have asked the same question: Where did the world come from? The answer is usually "created by God", such as the Genesis of the Bible. TaoTeChing asked the same question but got a very different answer. Lao-tzu said that the universe was created by the "Tao" instead of God or gods. Lao-tzu got his conclusion by finding the following phenomena through the observation of real life:

A tree as great as a man's embrace springs up from a small shoot; A terrace nine stories high begins with a pile of earth; A journey of a thousand miles starts under one’s feet. (Chapter 64)

The ten thousand things rise and fall while the Self watches their return. They grow and flourish and then return to the source. (Chapter 16) (Feng \& English, 1972)

YI Fu-sheng, Ph.D. student at Graduate School of Chinese Academy of Social Sciences, Assistant Professor at the History Department of Chinese Academy of Social Sciences. 
Lao-tzu found that all the visible objects are born or produced from a very small state, for example, a great tree grows up from a small seed and a tall terrace is built up from a pile of earth (Chapter 64). Lao-tzu also found that all the visible objects will eventually disappear in the invisible and this recurrent process is called "return to the source" in Chapter 16. In a word, Lao-tzu found that all the visible objects have the process from birth to development, then to decline. Since they are produced or born which means there is a mother who gives birth to them, they will not be the ultimate source of the universe. Then it is natural to draw a conclusion that the ultimate source of the universe is invisible. Similarly, it can be inferred that the ultimate source of the universe has no color or sound. Lao-tzu called this invisible, silent, colorless ultimate source of universe the “Tao”. So Lao-tzu described his conclusion with the following sagacious sentences:

Look, it cannot be seen-it is beyond form. Listen, it cannot be heard—it is beyond sound. Grasp, it cannot be held—it is intangible. (Chapter 14)

It cannot be seen, it cannot be heard. (Chapter 35) (Feng \& English, 1972)

Since the "Тao" is the ultimate source of the universe, there is nothing earlier than the "Tao". The "Tao" must appear earlier than the sky and gods:

I do not know from whence it comes. It is the forefather of the gods. (Chapter 4) (Feng \& English, 1972)

However, the invisible, silent, colorless "Tao" is not really empty; otherwise it could not give birth to the whole universe. There must be something inside of the "Tao" that can give birth to the universe. The thing inside of the "Tao" is called the "mother power which gives birth to the universe" by the famous Chinese scholar Gao Heng. However, in my opinion, it is very close to the concept "energy" in modern physics. The descriptions about the neither pure nor empty "Tao" in the TaoTeChing are as follows:

The ten thousand things are born of being. Being is born of not being. (Chapter 40)

The "Tao" is elusive and intangible. Oh, it is intangible and elusive, and yet within is image. Oh, it is elusive and intangible, and yet within is form. Oh, it is dim and dark, and yet within is essence. This essence is very real, and therein lays faith. (Chapter 21) (Feng \& English, 1972)

The "Tao" is the mother of everything and there is nothing else appearing earlier than the "Tao". So the "Tao" will not be controlled by anything including gods which means that the "Tao" runs spontaneously only following the law of itself or in another word, something natural. The "Tao" will not do anything consciously. This is why Lao-tzu said "the Tao follows what is natural” (Chapter 25) (Feng \& English, 1972). "The Tao abides in non-action” (Chapter 37) (Feng \& English, 1972).

In the natural state, the energy in the "Tao" should be scattered in all directions rather than focusing on a certain direction which will lead to the dispersion and weakening of energy. This is why the "Tao" is characterized by weakness.

As mentioned before, Lao-tzu found that all the physical materials would eventually perish and return to an invisible, silent and colorless state. They are not completely disappeared ("something” will never become a complete "nothing"), but return to their mother, the "Tao". Therefore, Lao-tzu came to the conclusion: The running track of the "Тао" is a circle which means that the "Tao" has produced everything, is producing everything and will produce everything and all things will finally return to the "Tao". So Lao-tzu described his conclusions as follows: 
Returning is the motion of the "Tao". (Chapter 40)

The ten thousand things rise and fall while the Self watches their return. They grow and flourish and then return to the source. (Chapter 16)

Being great, it flows. I flow far away. Having gone far, it returns. (Chapter 25) (Feng \& English, 1972)

The "Tao" constantly gives birth to everything and accepts the return of all things, so the "Tao" can never be exhausted. This is described in the follow chapters:

The “Tao" is an empty vessel; it is used, but never filled. (Chapter 4)

The more it moves, the more it yields. (Chapter 5)

Use it; it will never fail. (Chapter 6)

It cannot be seen, it cannot be heard, and yet it cannot be exhausted. (Chapter 35) (Feng \& English, 1972)

\section{The Relations of the "Tao" and Human Society}

So far, we deduce many properties of the "Tao" by analyzing the text of TaoTeChing: The "Tao" is the mother of all things, the origin of the universe and everything will return to it after they die and disappear; The "Tao" has no shape, no color and no sound but the "Tao" is not completely empty which implies that there is energy in it; The running track of the "Tao" is a circle; The "Tao" is characterized by weakness. The purpose of describing those philosophic thoughts is to give some instructive lessons to human society. Lao-tzu believed that human society should follow the "Tao" and do something similar. Especially, the rulers should do nothing and the world will run very well automatically. The rulers should be characterized by weakness and should not invade other countries or interfere in people's lives. The question is why human society should follow the “Tao”? Why couldn't human do what they want to do? There are two reasons:

(1) This involves the concept of the “Te” (德) (the “Te” has also been translated as “Virtue”):

All things arise from "Tao". They are nourished by Virtue. They are formed from matter. They are shaped by environment. (Chapter 51)

Therefore all things arise from "Tao". By Virtue they are nourished, developed, cared for, sheltered, comforted, grown, and protected. (Chapter 51) (Feng \& English, 1972)

The word "Te" means "get something" in ancient Chinese language. To be more specific, the word "Te" in TaoTeChing means that everything gets its body and life from the "Tao". Through the above quotation, we could know that the "Tao" not only gives birth to things and forms the shapes of things but also exists in the bodies of all things in the form of the "Te". The "Te" is the essential attribute of all things and produces nurture to make everything continue to grow up. Since the "Te" is the essential attribute of everything, all things must be in accordance with the "Te" and the "Tao". A man who follows the "Tao" is in line with his own nature. By contrast, a man who is against the "Tao" is contrary to his nature which is bound to be not long. In this way, the “Tao” has connected with all things including human beings and human society:

Man follows Earth. Earth follows heaven. Heaven follows the Tao. (Chapter 25) (Feng \& English, 1972)

(2) Lao-tzu was also inspired by real life: 
Better to stop short than fill to the brim. Over sharpen the blade, and the edge will soon blunt. Amass a store of gold and jade, and no one can protect it. (Chapter 9)

Yield and overcome; Bend and be straight; Empty and be full; Wear out and be new; Have little and gain; Have much and be confused. (Chapter 22)

High winds do not last all morning. Heavy rain does not last all day. Why is this? Heaven and Earth! If heaven and Earth cannot make things eternal, how is it possible for man? (Chapter 23)

Why is the sea king of a hundred streams? Because it lies below them, therefore it is the king of a hundred streams. (Chapter 66)

A man is born gentle and weak. At his death he is hard and stiff. Green plants are tender and filled with sap. At their death they are withered and dry. (Chapter 76)

Under heaven nothing is more soft and yielding than water. Yet for attacking the solid and strong, nothing is better. (Chapter 78) (Feng \& English, 1972)

Lao-tzu found the facts in real life that things which are weak and soft can live longer and better than others and things which are strong and hard could not last for long. Then he came to the conclusion that weak and soft is better for human society. Some scholars do not understand this so that they could not understand why the human society should follow the "Tao". They believe that the "Tao" and humanity are not related and we could not pull them together.

In short, the book, TaoTeChing, seems disorganized but has its inner clues. Lao Tzu abstracted some principles through the observation of daily life and made some further deductions. Then he got a totally new understanding of the universe and human society.

\section{Conclusion}

By analyzing the inner clues of TaoTeChing, We can understand now how Lao-tzu got his conclusions: Lao-tzu found that all the visible things are produced or born by something, which means that these observable things could not be the ultimate source of the universe. The ultimate source of the universe must be invisible and has no color or sound. Lao-tzu called it the "Tao". Based on this, Lao-tzu described all attributes of the “Tao".

The purpose of describing the "Tao" is to serve Lao-tzu's political theory. Everything gets its body and life from the "Tao", so that human society should follow the "Tao" and do something similar to the "Tao". It means that human society should be characterized by weakness and doing nothing.

\section{References}

Feng, G., \& English, J. (1972). TaoTeChing. New York: Random House. 